\title{
Infectious Featured Article \\ Sputum Active Polymyxin Lipopeptides: Activity against Cystic Fibrosis Pseudomonas aeruginosa Isolates and Their Interactions with Sputum Biomolecules
}

Elena K. Schneider-Futschik, ${ }^{\dagger, \ddagger \odot}$ Olivia K. A. Paulin, ${ }^{\dagger}$ Daniel Hoyer, ${ }^{\ddagger}, \|$, II Kade D. Roberts, $^{\S}$

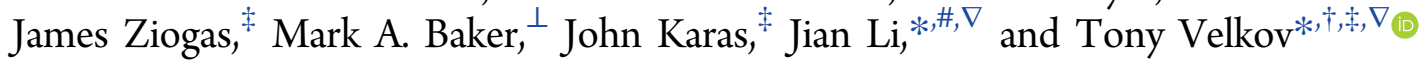

${ }^{\dagger}$ Drug Delivery, Disposition and Dynamics, Monash Institute of Pharmaceutical Sciences, Monash University, Parkville, Victoria 3052, Australia

${ }^{\ddagger}$ Department of Pharmacology and Therapeutics, School of Biomedical Sciences, Faculty of Medicine, Dentistry and Health Sciences, The University of Melbourne, Parkville, Victoria 3010, Australia

${ }^{\S}$ Medicinal Chemistry, Monash Institute of Pharmaceutical Sciences, Monash University, Parkville, Victoria 3052, Australia

"The Florey Institute of Neuroscience and Mental Health, The University of Melbourne, 30 Royal Parade, Parkville, Victoria 3052, Australia

${ }^{\perp}$ Priority Research Centre in Reproductive Science, School of Environmental and Life Sciences, University of Newcastle, Callaghan, New South Wales 2308, Australia

${ }^{\#}$ Monash Biomedicine Discovery Institute, Department of Microbiology, Monash University, Clayton, Victoria 3800, Australia

IIDepartment of Molecular Medicine, The Scripps Research Institute, 10550 N. Torrey Pines Road, La Jolla, California 92037, United States

\section{Supporting Information}

ABSTRACT: The mucoid biofilm mode of growth of Pseudomonas aeruginosa ( $P$. aeruginosa) in the lungs of cystic fibrosis patients makes eradication of infections with antibiotic therapy very difficult. The lipopeptide antibiotics polymyxin B and colistin are currently the last-resort therapies for infections caused by multidrugresistant $P$. aeruginosa. In the present study, we investigated the antibacterial activity of a series of polymyxin lipopeptides (polymyxin B, colistin, FADDI-003, octapeptin $\mathrm{A}_{3}$, and polymyxin $\mathrm{A}_{2}$ ) against a panel of polymyxin-susceptible and polymyxin-resistant $P$. aeruginosa cystic fibrosis isolates grown under planktonic or biofilm conditions in artificial sputum and their interactions with sputum component biomolecules. In sputum media under planktonic conditions, the lipopeptides FADDI-003 and octapeptin $\mathrm{A}_{3}$ displayed very promising activity against the polymyxin-resistant isolate FADDIPA066 (polymyxin B minimum inhibitory concentration (MIC) $=32 \mathrm{mg} / \mathrm{L}$ ), while retaining their activity against the polymyxin-sensitive strains FADDI-PA021 (polymyxin $\mathrm{B} \mathrm{MIC}=1 \mathrm{mg} / \mathrm{L}$ ) and FADDI-PA020 (polymyxin B MIC $=2 \mathrm{mg} / \mathrm{L}$ ).

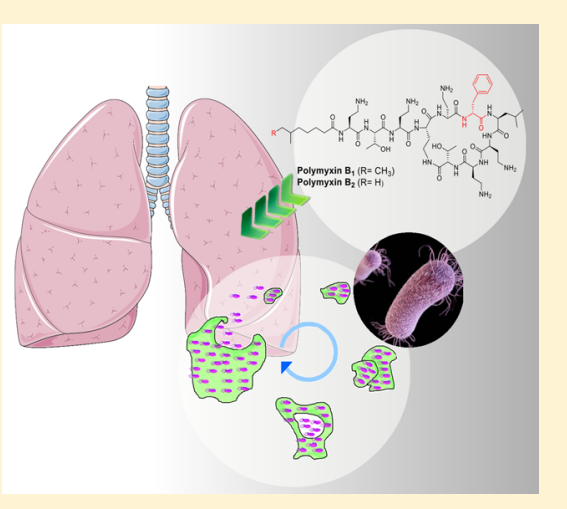
Polymyxin $\mathrm{A}_{2}$ was only effective against the polymyxin-sensitive isolates. However, under biofilm growth conditions, the hydrophobic lipopeptide FADDI-003 was inactive compared to the more hydrophilic lipopeptides, octapeptin $A_{3}$, polymyxin $A_{2}$, polymyxin $B$, and colistin. Transmission electron micrographs revealed octapeptin $\mathrm{A}_{3}$ caused reduction in the cell numbers in biofilm as well as biofilm disruption/“antibiofilm" activity. We therefore assessed the interactions of the lipopeptides with the component sputum biomolecules, mucin, deoxyribonucleic acid (DNA), surfactant, F-actin, lipopolysaccharide, and phospholipids. We observed the general trend that sputum biomolecules reduce lipopeptide antibacterial activity. Collectively, our data suggests that, in the airways, lipopeptide binding to component sputum biomolecules may reduce antibacterial efficacy and is dependent on the physicochemical properties of the lipopeptide.

KEYWORDS: cystic fibrosis, P. aeruginosa, lipopeptides, polymyxins, nonmucoid "planktonic" growth, mucoid "biofilm" growth, biofilm, sputum

C ystic fibrosis (CF) is the most common recessively inherited disease caused by mutations in a gene that encodes the CF transmembrane conductance regulator (CFTR) protein. ${ }^{1}$ One of the consequences of a defective CFTR gating function is the development of thick mucus accumulation in the lungs which promotes bacterial infections. Approximately $80 \%$ of all CF lung infections in adult patients are caused by the Gram-negative pathogen Pseudomonas aeruginosa ( $P$. aeruginosa). ${ }^{2}$ Once $P$. aeruginosa has colonized the CF lung, the infection is nearly

Received: November 19, 2017

Published: March 22, 2018 
impossible to eradicate. Notably, $P$. aeruginosa chronic lung infections are the main cause of death in CF patients. ${ }^{3}$ P. aeruginosa is able to switch from planktonic growth to biofilm growth, which provides tolerance to the host's inflammatory defense mechanisms and shields the bacteria from the aerobic respiratory zone. $^{3-7}$ Due to these highly adaptive resistance mechanisms, $P$. aeruginosa is capable of persisting in the lungs of CF patients irrespective of their intensive antibiotic treatment regimens. ${ }^{8-10}$

The decline in the development of antibiotics with novel modes of action, combined with the emergence of Gram-negative pathogens with multidrug resistance, is of grave concern, particularly for chronic infections such as $P$. aeruginosa in the lungs of CF patients. Polymyxin B and colistin (polymyxin E) are being used as last-resort therapy against Gram-negative infections. ${ }^{11}$ Unfortunately, resistance to polymyxins in both community and nosocomially acquired infections is increasingly more common, ${ }^{12,13}$ which essentially means limited treatment options are available for the treatment of life-threatening infections. This is compounded by the widespread emergence of mobilized colistin resistance $(m c r-1)$ plasmid-borne polymyxin resistance; clinicians are now confronted with the reality of Gram-negative infections that are resistant even to the last line-resort polymyxins. ${ }^{14-16}$

Biofilm formation is a major factor that contributes to the pathophysiology of $P$. aeruginosa CF lung infections. ${ }^{3}$ Biofilm consists of bacteria interconnected to extracellular material such as polysaccharides, protein, and deoxyribonucleic acid (DNA) that together form a matrix. ${ }^{3}$ Moreover, the hyper-mutability of $P$. aeruginosa growing in biofilm promotes the emergence of antibiotic resistance mutations which are selected for under the pressure of the repeated courses of antibiotics that CF patients often receive. ${ }^{3}$ The minimal inhibitory concentration (MIC) of antibiotics against bacteria growing in biofilm can be up to 1000 fold higher compared to the same isolate growing planktonically. ${ }^{3,17-19}$ The underlying causes may include restricted penetration of the antibiotic through the recalcitrant biofilm matrix and the lower metabolic activity of bacteria when growing in biofilm. 3,20

In the present study, we evaluated the activity of a series of natural (polymyxin $B$ and $A_{2}$, colistin, and octapeptin $A_{3}$ ) and synthetic (FADDI-003) lipopeptides which display varying degrees of hydrophobicity and hydrophilicity against $P$. aeruginosa $\mathrm{CF}$ isolates grown under planktonic and biofilm conditions. Furthermore, we investigated the impact of sputum composite biomolecules (F-actin, DNA, mucin, phospholipids, surfactant, and lipopolysaccharide [LPS]) on the antipseudomonal activity of the lipopeptides. The present findings highlight these lipopeptides as promising candidates for development as inhaled antibiotics for the treatment of problematic $P$. aeruginosa $C F$ lung infections.

\section{RESULTS AND DISCUSSION}

The naturally occurring polymyxins are deca-peptides which carry five positive charges and display a narrow spectrum against Gram-negative bacteria. ${ }^{11}$ Octapeptins are a unique polymyxinlike class of cationic octa-peptides that carry only four positive charges. Moreover, unlike the naturally occurring polymyxins, octapeptins exhibit a broader spectrum that also includes Grampositive bacteria, yeast, protozoa, and filamentous fungi. ${ }^{21-28}$

Inhaled polymyxin therapy achieves high local exposure in the respiratory tract. ${ }^{29}$ Our group has recently demonstrated that both extrinsic death receptors and intrinsic mitochondrial pathways are involved in polymyxin induced toxicity in human lung epithelial A459 cells. $^{30}$ Dose-limiting nephrotoxicity remains the
Achilles' heel of polymyxins which can occur in up to $60 \%$ of patients receiving intravenous polymyxins. Azad et al. have demonstrated that the coadministration of methionine significantly ameliorated polymyxin-induced nephrotoxicity and decreased mitochondrial superoxide production in renal tubular cells. ${ }^{31}$

In the present study, we examined the antipseudomonal activity of three polymyxin lipopeptides of varying physiochemical properties, namely, the hydrophobic FADDI-003 and the more hydrophilic polymyxin $A_{2}$ and octapeptin $A_{3}$; the two clinically used polymyxins, polymyxin $\mathrm{B}$ and colistin, were utilized as comparators (Figure 1). The more hydrophobic FADDI-003 is a synthetic polymyxin $\mathrm{B}_{1}$ derivative that differs in an $\mathrm{N}$-terminal biphenylacyl fatty chain and a L-octglycine at position 7 compared to the N-terminal 6-methyloctanoyl fatty acid chain and L-Leu ${ }^{7}$ in the native polymyxin $B_{1}$. The more hydrophilic polymyxin $A_{2}$ has an $\mathrm{N}$-terminal 6-methylheptanoyl fatty acid chain, D-diaminobutyric acid at position 3, and L-Thr at position 7. The naturally occurring octapeptin $\mathrm{A}_{3}$ has an $\mathrm{N}$-terminal 3-hydroxydecanoyl fatty acid chain, a truncated linear segment with only a D-diaminobutyric acid at position 3, and an L-Leu at position 10.

Previous studies that examined the sputum penetration of antibiotics employed a dialysis method to assess the concentration of unbound antibiotic in the presence of mucin or sputum. ${ }^{32,33}$ Here, we have used the more direct approach of measuring the antibacterial activity of our lipopeptides against $P$. aeruginosa grown under planktonic vs biofilm conditions in artificial sputum, and we also examined the impact of individual component sputum biomolecules.

The antibacterial activity of the lipopeptides was screened against a panel of polymyxin-sensitive and -resistant $P$. aeruginosa CF isolates in standard CAMBH microbiological media (Table 1). Lipopeptides FADDI-003 (MICs $2-4 \mathrm{mg} / \mathrm{L}$ ) and octapeptin $\mathrm{A}_{3}$ (MICs $2-16 \mathrm{mg} / \mathrm{L}$ ) showed very promising activity against the polymyxin-resistant isolates (polymyxin B and colistin MICs $16-128 \mathrm{mg} / \mathrm{L}$ ), while retaining activity against polymyxin-sensitive isolates (FADDI-003 and octapeptin $\mathrm{A}_{3}$ MICs $1-8 \mathrm{mg} / \mathrm{L}$; polymyxin $B$ and colistin MICs $0.25-4 \mathrm{mg} / \mathrm{L}$ ). Polymyxin $\mathrm{A}_{2}$ displayed similar antibacterial activity as polymyxin $\mathrm{B}$ and colistin against the polymyxin-resistant isolates (MICs $>32 \mathrm{mg} / \mathrm{L}$ ) and the polymyxin-sensitive isolates (MICs $0.25-1 \mathrm{mg} / \mathrm{L}$ ).

Artificial sputum media (ASM) closely mimics the sputum of CF patients and consists of mucin, DNA, surfactant, phospholipids, salt, and amino acids allowing $P$. aeruginosa to form microcolonies and develop biofilm like structures. ${ }^{34}$ The activity of clinically achievable lung concentrations of the lipopeptides $(1-256 \mathrm{mg} / \mathrm{L})$ was tested against the reference strain $P$. aeruginosa FADDI-PA021 (polymyxin B MIC $=1 \mathrm{mg} / \mathrm{L}$ ) and the paired $P$. aeruginosa $\mathrm{CF}$ isolates FADDI-PA020 (polymyxin B MIC $=2 \mathrm{mg} / \mathrm{L}$ ) and FADDI-PA066 (polymyxin $\mathrm{B}$ MIC $=32 \mathrm{mg} / \mathrm{L}$ ) under planktonic growth conditions. ${ }^{29}$ Against the polymyxin-sensitive CF isolate FADDI-PA020, all of the lipopeptides effectively reduced cell viability (reduction to $\sim 30 \%$ cell viability at $2 \mathrm{mg} / \mathrm{L}$ ) when grown planktonically in sputum (Figure 2). In contrast, against the polymyxin-resistant CF isolate FADDI-PA066 only FADDI-003 and octapeptin $\mathrm{A}_{3}$ displayed good activity (reduction to $\sim 30 \%$ cell viability at $8 \mathrm{mg} / \mathrm{L}$ ), whereas polymyxin $\mathrm{B}, \mathrm{A}_{2}$, and colistin were inactive even at $128 \mathrm{mg} / \mathrm{L}$ (Figure 3 ). In the case of the $P$. aeruginosa polymyxin-sensitive reference strain FADDI-PA021, all of the lipopeptides except colistin effectively reduced cell viability when grown planktonically in sputum (reduction to $\sim 30 \%$ cell viability at $1 \mathrm{mg} / \mathrm{L}$; Figure S1). Overall, these results demonstrate that the lipopeptides display good activity, particularly octapeptin $\mathrm{A}_{3}$ and 


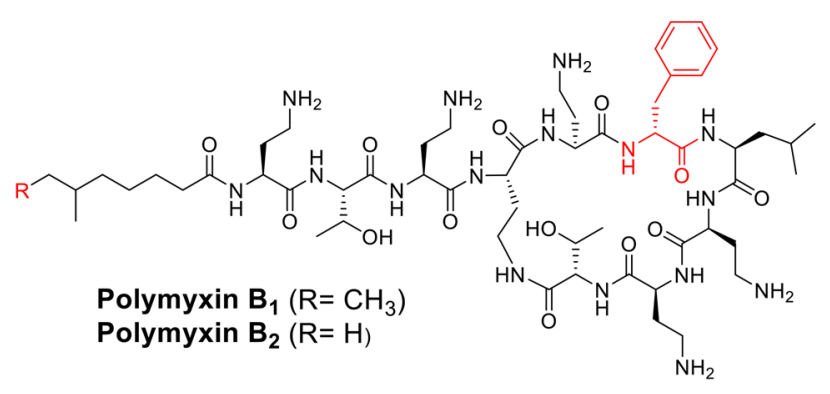

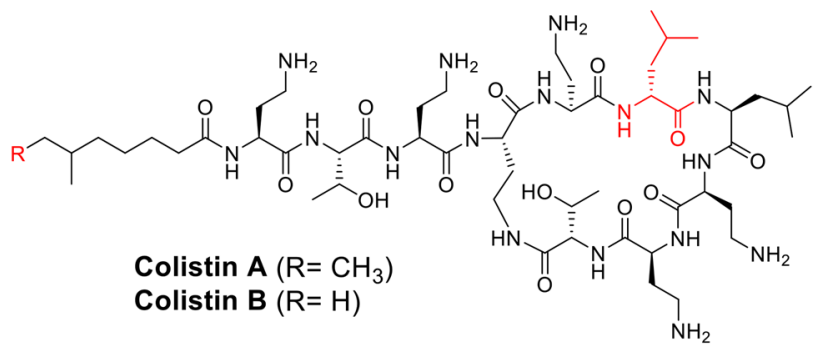

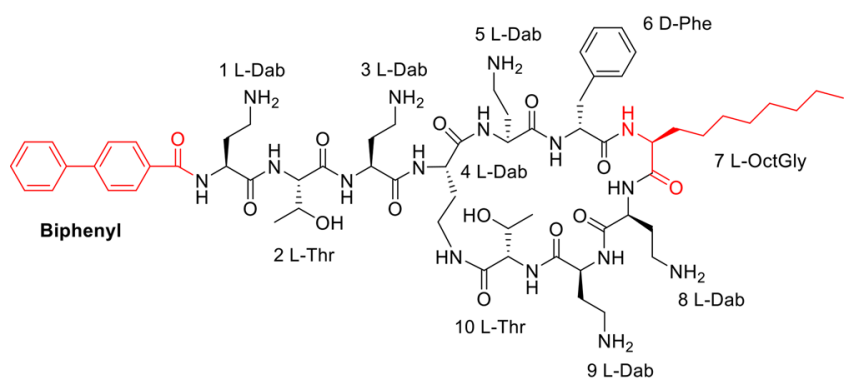

FADDI-003
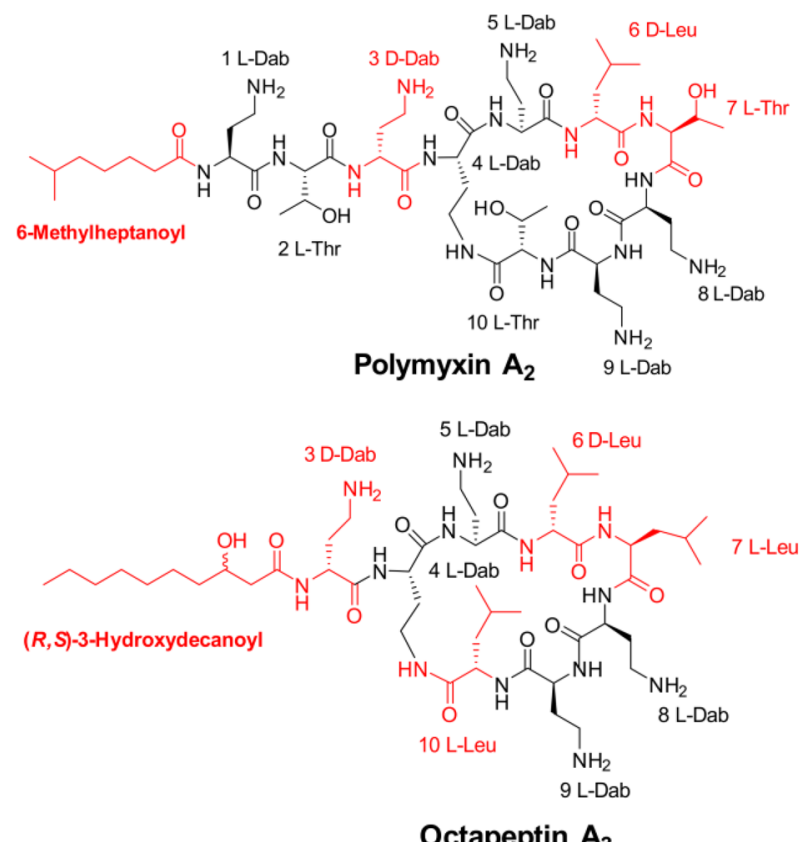

Octapeptin $\mathbf{A}_{3}$

Figure 1. Chemical structures of polymyxin $B$, colistin, FADDI-003, polymyxin $A_{2}$, and octapeptin $A_{3}$. Structure differences from the polymyxin $B_{1}$ core scaffold are shown in red.

FADDI-003, against $P$. aeruginosa CF isolates growing planktonically in sputum.

The understanding of pharmacokinetic (PK) and pharmacodynamics (PD) principles of antibacterial agents provides
Table 1. In Vitro Antibacterial Activity of Polymyxin Lipopeptides against CF $P$. aeruginosa Isolates

\begin{tabular}{|c|c|c|c|c|c|}
\hline \multirow[b]{2}{*}{$\begin{array}{l}P . \text { aeurignosa } \\
\text { isolate }\end{array}$} & \multicolumn{5}{|c|}{ minimum inhibitory concentration $(\mathrm{mg} / \mathrm{L})$} \\
\hline & $\mathrm{PMB}^{a}$ & $\mathrm{COL}^{b}$ & $\begin{array}{l}\text { FADDI- } \\
003\end{array}$ & $\begin{array}{c}\text { polymyxin } \\
\mathrm{A}_{2}\end{array}$ & $\begin{array}{c}\text { octapeptin } \\
\mathrm{A}_{3}\end{array}$ \\
\hline \multicolumn{6}{|c|}{ Polymyxin Susceptible } \\
\hline ATCC 27853 & 0.5 & 1 & 4 & 0.5 & 2 \\
\hline FADDI-PA002 & 0.5 & 0.25 & 8 & 0.25 & 2 \\
\hline FADDI-PA022 & 1 & 1 & 4 & 0.5 & 4 \\
\hline FADDI-PA091 & 1 & 0.5 & 2 & 0.5 & 4 \\
\hline FADDI-PA025 & 2 & 2 & 4 & 1 & 4 \\
\hline FADDI-PA001 & 0.5 & 0.5 & 1 & 0.5 & 4 \\
\hline FADDI-PA038 & 1 & 1 & 4 & 1 & 8 \\
\hline FADDI-PA021 & 2 & 2 & 1 & $<1$ & $2-4$ \\
\hline FADDI-PA020 & 4 & 4 & 2 & $<1$ & 4 \\
\hline \multicolumn{6}{|c|}{ Polymyxin Resistant } \\
\hline FADDI-PA092 & 16 & 16 & 4 & $>32$ & 4 \\
\hline FADDI-PA093 & 32 & 32 & 4 & $>32$ & 8 \\
\hline FADDI-PA066 & 32 & $>128$ & 4 & $>128$ & 16 \\
\hline FADDI-PA065 & $>32$ & $>32$ & 4 & $>32$ & 4 \\
\hline FADDI-PA070 & $>32$ & $>32$ & 2 & $>32$ & 2 \\
\hline FADDI-PA069 & $>32$ & NA & 2 & NA & NA \\
\hline FADDI-PA068 & $>32$ & $>32$ & 4 & $>32$ & 2 \\
\hline FADDI-PA062 & $>32$ & $>32$ & 2 & $>32$ & 4 \\
\hline FADDI-PA060 & $>128$ & $>32$ & 2 & $>32$ & 0.5 \\
\hline
\end{tabular}

essential information for effective dosage regimens and minimizing resistance. ${ }^{35}$ However, most PK/PD studies are conducted on planktonically growing bacteria, and the results do not translate into biofilm growth conditions commonly seen in the CF lung. ${ }^{3,36,37}$ In the next tier of this study, we investigated the activity of each lipopeptide against the reference strain $P$. aeruginosa FADDI-PA021 (polymyxin B MIC $=1 \mathrm{mg} / \mathrm{L}$ ) and the paired CF isolates $P$. aeruginosa FADDI-PA066 (polymyxin $\mathrm{B}$ MIC $=$ $32 \mathrm{mg} / \mathrm{L}$ ) and FADDI-PA020 (polymyxin B MIC = $2 \mathrm{mg} / \mathrm{L}$ ) under biofilm formation in a sputum medium. Against the polymyxin-sensitive CF isolate FADDI-PA020, the more hydrophilic lipopeptides colistin and polymyxin $\mathrm{A}_{2}$ displayed good activity (reduction to $\sim 30 \%$ cell viability at $32 \mathrm{mg} / \mathrm{L}$ ) under biofilm formation in a sputum medium (Figure 4). In contrast, the comparably more hydrophobic lipopeptides octapeptin $\mathrm{A}_{3}$ (reduction to $\sim 25 \%$ cell viability at $64 \mathrm{mg} / \mathrm{L}$ ), polymyxin $\mathrm{B}$ (reduction to $\sim 50 \%$ cell viability at $128 \mathrm{mg} / \mathrm{L}$ ), and FADDI-003 (reduction to $\sim 50 \%$ cell viability at $256 \mathrm{mg} / \mathrm{L}$ ) were significantly less active. Against the polymyxin-resistant CF isolate FADDIPA066, only octapeptin $\mathrm{A}_{3}$ displayed good activity (reduction to $\sim 25 \%$ cell viability at $32 \mathrm{mg} / \mathrm{L}$ ) under biofilm formation in a sputum medium (Figure 5). In comparison, polymyxin B (reduction to $\sim 40 \%$ cell viability at $128 \mathrm{mg} / \mathrm{L}$ ), colistin (reduction to $\sim 30 \%$ cell viability at $128 \mathrm{mg} / \mathrm{L}$ ), and polymyxin $\mathrm{A}_{2}$ (reduction to $\sim 20 \%$ cell viability at $128 \mathrm{mg} / \mathrm{L}$ ) were significantly less active. FADDI-003 was completely inactive up to $256 \mathrm{mg} / \mathrm{L}$. In the case of the $P$. aeruginosa reference strain FADDI-PA021, polymyxin B (reduction to $\sim 25 \%$ cell viability at $32 \mathrm{mg} / \mathrm{L}$ ), colistin (reduction to $\sim 25 \%$ cell viability at $64 \mathrm{mg} / \mathrm{L}$ ), polymyxin $\mathrm{A}_{2}$ (reduction to $\sim 45 \%$ cell viability at $32 \mathrm{mg} / \mathrm{L}$ ), and octapeptin A3 (reduction to $\sim 45 \%$ cell viability at $32 \mathrm{mg} / \mathrm{L}$ ) effectively reduced cell viability when grown under biofilm formation in sputum (Figure S2). FADDI-003 was completely inactive up to $256 \mathrm{mg} / \mathrm{L}$.

Interestingly, the very hydrophobic lipopeptide FADDI-003 was completely inactive against all the $P$. aeruginosa isolates under 

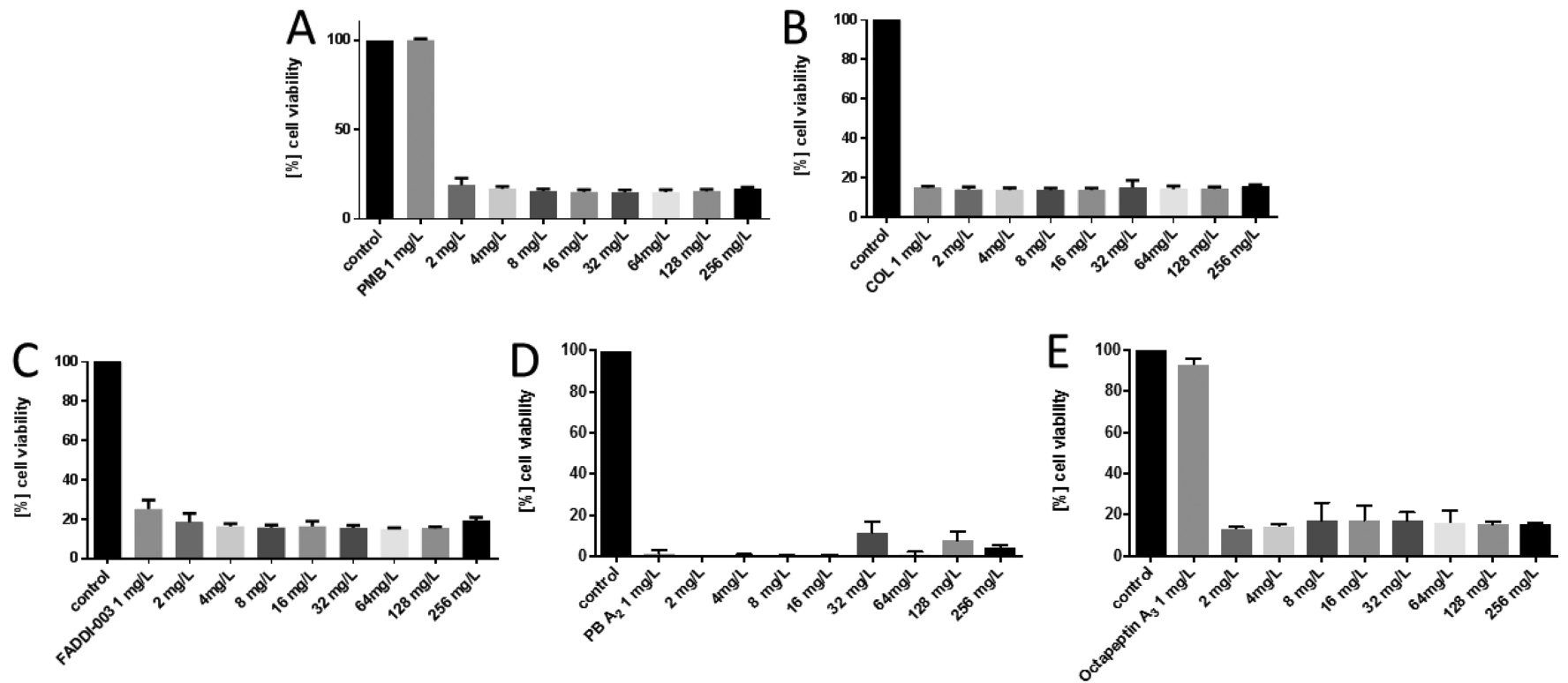

Figure 2. Activity of (A) polymyxin $\mathrm{B}$, (B) colistin, (C) FADDI-003, (D) polymyxin $\mathrm{A}_{2}$, and (E) octapeptin $\mathrm{A}_{3}$ against $P$. aeruginosa CF isolate FADDIPA020 grown under planktonic conditions in artificial sputum media. Data are presented as the mean $\pm \operatorname{SD}(n=3)$.
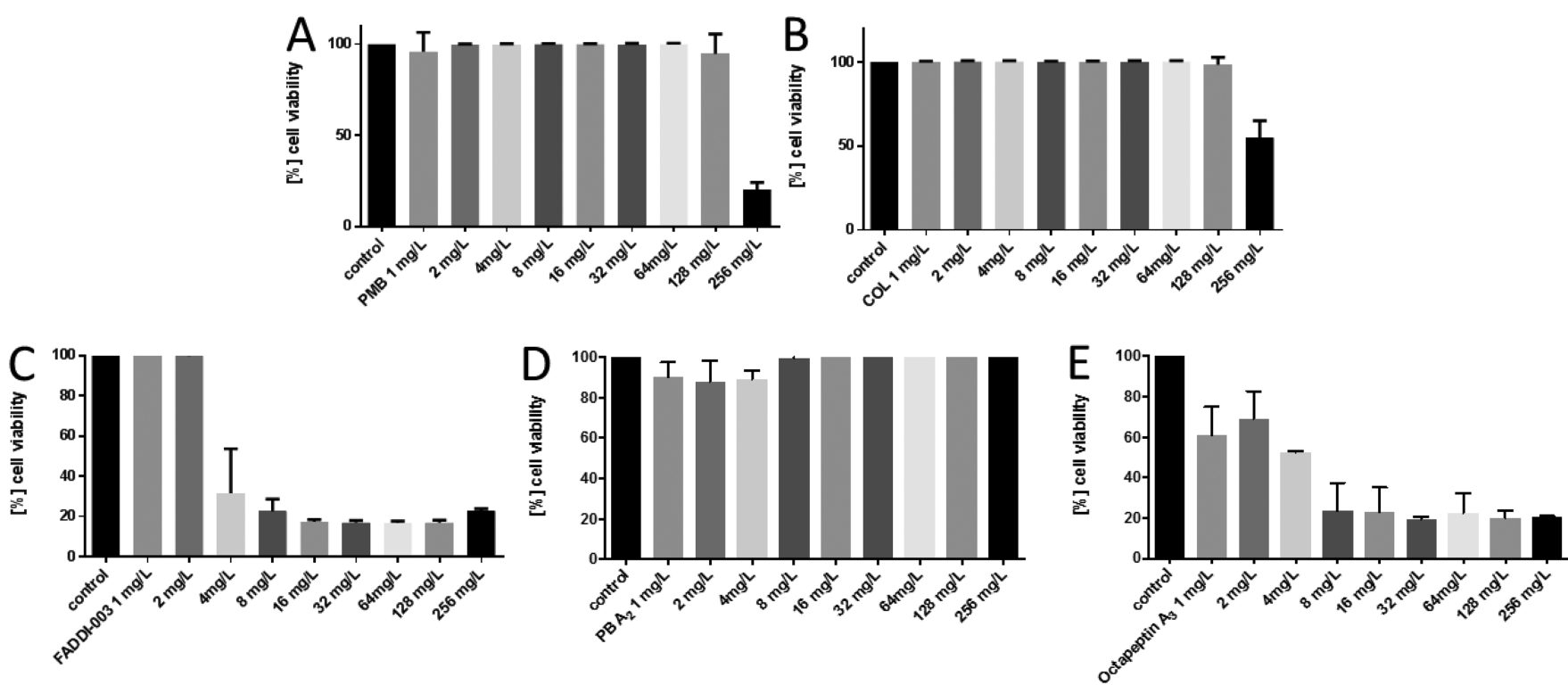

Figure 3. Activity of (A) polymyxin B, (B) colistin, (C) FADDI-003, (D) polymyxin $\mathrm{A}_{2}$, and (E) octapeptin $\mathrm{A}_{3}$ against P. aeruginosa CF isolate FADDIPA066 grown under planktonic conditions in artificial sputum media. Data are presented as the mean $\pm \operatorname{SD}(n=3)$.

biofilm conditions ( $\sim 100 \%$ cell viability at $256 \mathrm{mg} / \mathrm{L})$. Although FADDI-003 has good activity against both the polymyxinsensitive and -resistant isolates under planktonic growth conditions, we postulate that its poor activity under biofilm conditions is most likely due to its very hydrophobic physicochemical characteristics which inhibit its ability to diffuse through the outer biofilm layer. In line with this postulate, it has been show that the increment of hydrophobicity decreases the diffusion kinetics of nanoparticles in mucus. ${ }^{38}$

In line with our ASM results, transmission electron microscopy imaging of $P$. aeruginosa FADDI-PA066 cells growing in biofilm revealed that octapeptin $\mathrm{A}_{3}$ treatment $(16 \mathrm{mg} / \mathrm{L} ; 1 \times$ MIC) reduced the cell numbers as well as exerting "antibiofilm" activity/biofilm disruption compared to biofilms treated with colistin (128 mg/L; 1× MIC) (Figure 6). Notably, treatment with octapeptin $\mathrm{A}_{3}$ produced a drastic disruption of the bacterial outer membrane structure with the loss of intracellular contents. This is in stark contrast from the cells treated with colistin wherein a blebbing effect with vesicular protrusions from the outer membrane is observed that is associated with polymyxin exposure of Gram-negative cells (Figure 6). ${ }^{39}$ The untreated cells exhibited no membrane disruption.

Sputum significantly inhibits the antibacterial activity of tobramycin, an aminoglycoside antibiotic commonly used via inhalation for the treatment of $P$. aeruginosa lung infections in CF patients. ${ }^{40}$ Moreover, it has been shown that the activity of the lipopeptide antibiotic daptomycin is inhibited by pulmonary biomolecules such as surfactant. ${ }^{41}$ Hence, we hypothesized that binding of the lipopeptides to sputum component biomolecules reduces their antibacterial activity. Previous studies aimed at determining the impact of sputum components on antibiotic binding examined mucin, glycoproteins, or DNA using radioenzymatic 

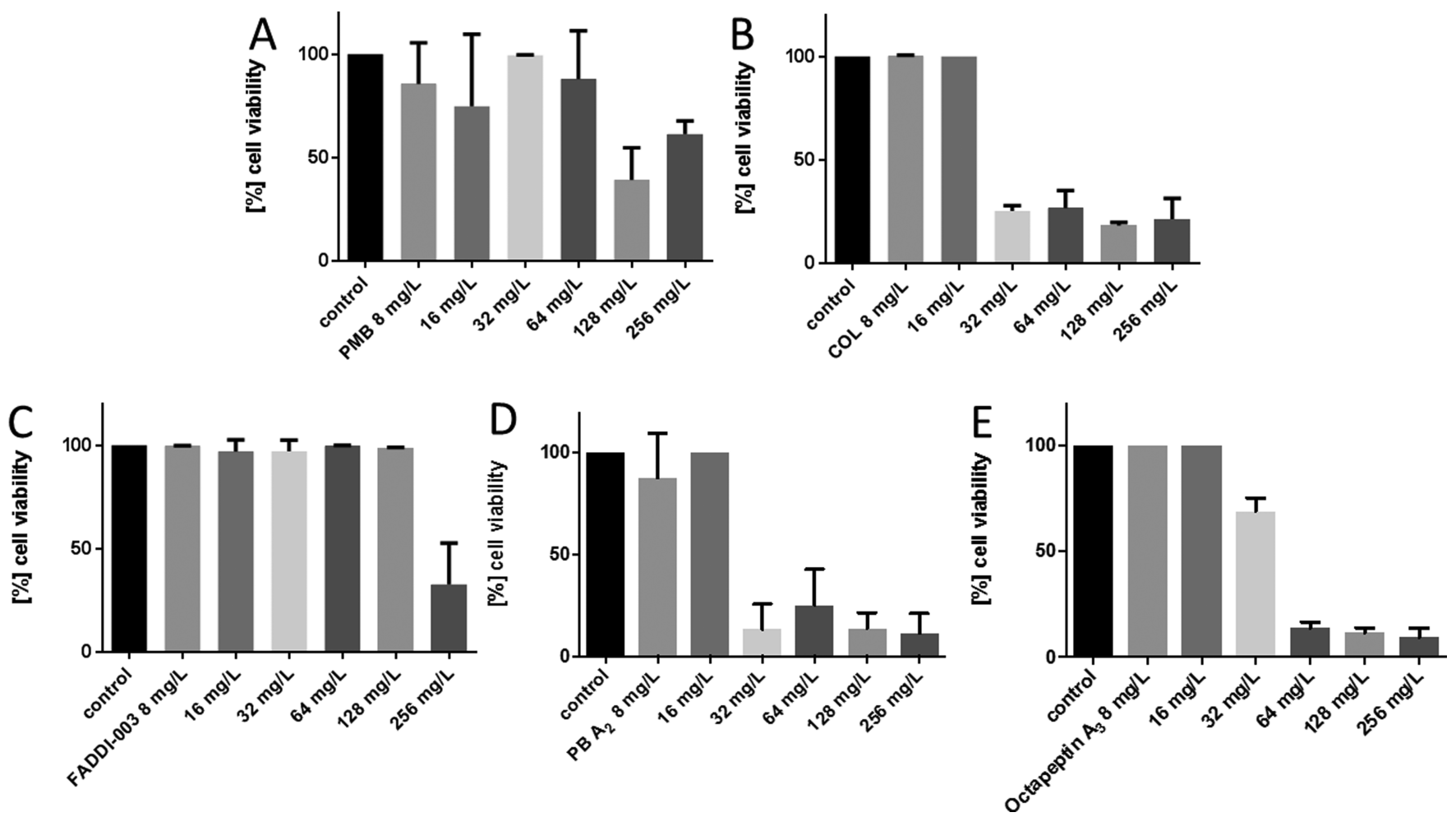

Figure 4. Activity of (A) polymyxin B, (B) colistin, (C) FADDI-003, (D) polymyxin $\mathrm{A}_{2}$, and (E) octapeptin $\mathrm{A}_{3}$ against P. aeruginosa CF isolate FADDIPA020 grown under biofilm conditions in artificial sputum media. Data are presented as the mean \pm SD $(n=3)$.

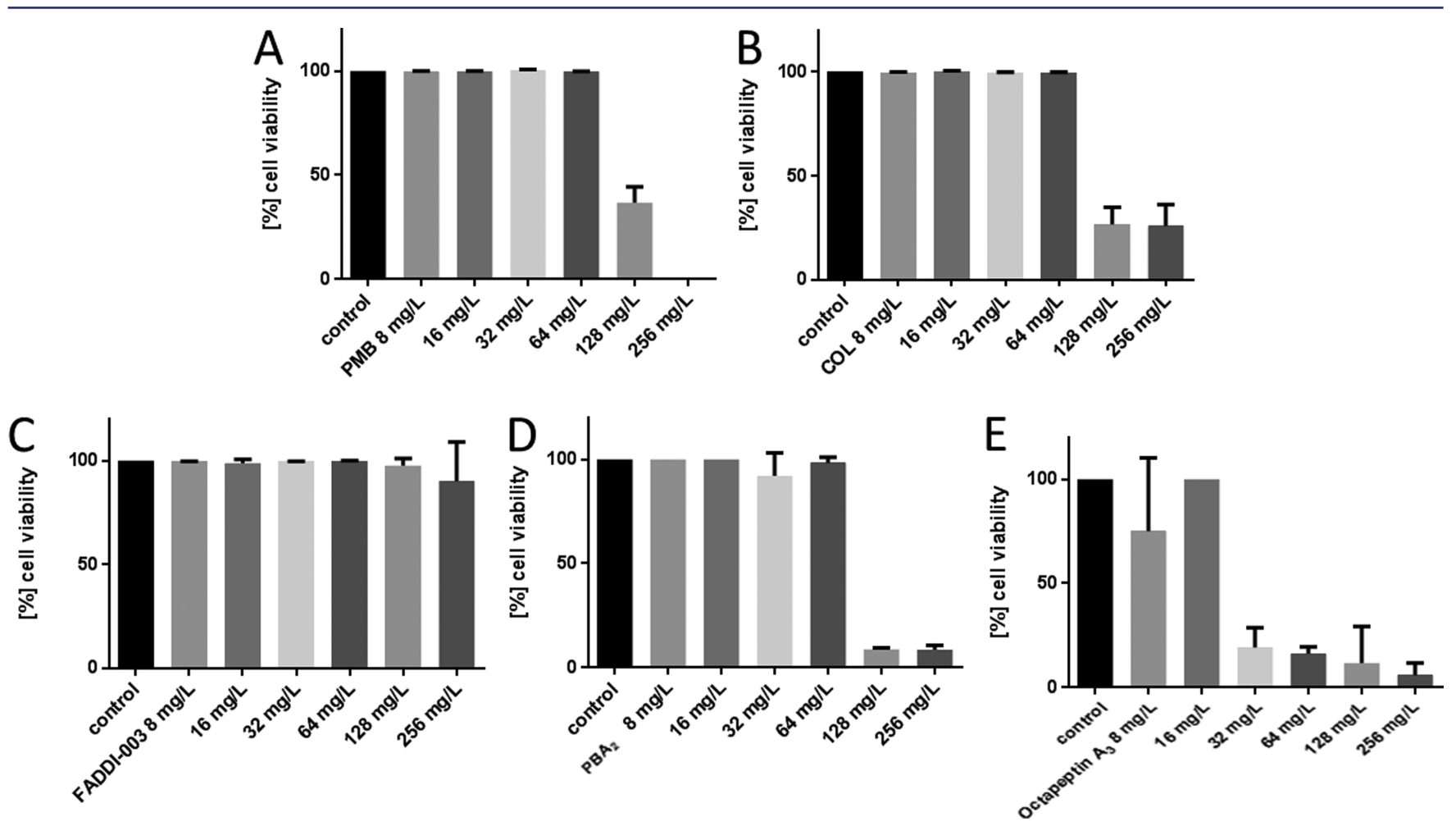

Figure 5. Activity of (A) polymyxin B, (B) colistin, (C) FADDI-003, (D) polymyxin $\mathrm{A}_{2}$, and (E) octapeptin $\mathrm{A}_{3}$ against P. aeruginosa CF isolate FADDIPA066 grown under biofilm conditions in artificial sputum media. Data are presented as the mean \pm SD $(n=3)$.

assays, MIC determination, or immunofluorescence. ${ }^{33,40,42,43}$ In the present study, we examined the impact of each individual sputum biomolecule (F-actin, DNA, phospholipids, surfactant, mucin, and LPS) in CAMBH media on the activity of our lipopeptides (Figures S3-S5). We tested the activity of the lipopeptides at $2 \mathrm{mg} / \mathrm{L}$ in combination with a sputum biomolecule at $125 \mathrm{mg} / \mathrm{L}$ against $P$. aeruginosa strains FADDI-PA020 (polymyxin B MIC $=2 \mathrm{mg} / \mathrm{L}$ ) and FADDI-PA066 (polymyxin B $\mathrm{MIC}=32 \mathrm{mg} / \mathrm{L})$ and the reference strain FADDI-PA021 (polymyxin B MIC $=1 \mathrm{mg} / \mathrm{L}$ ). 

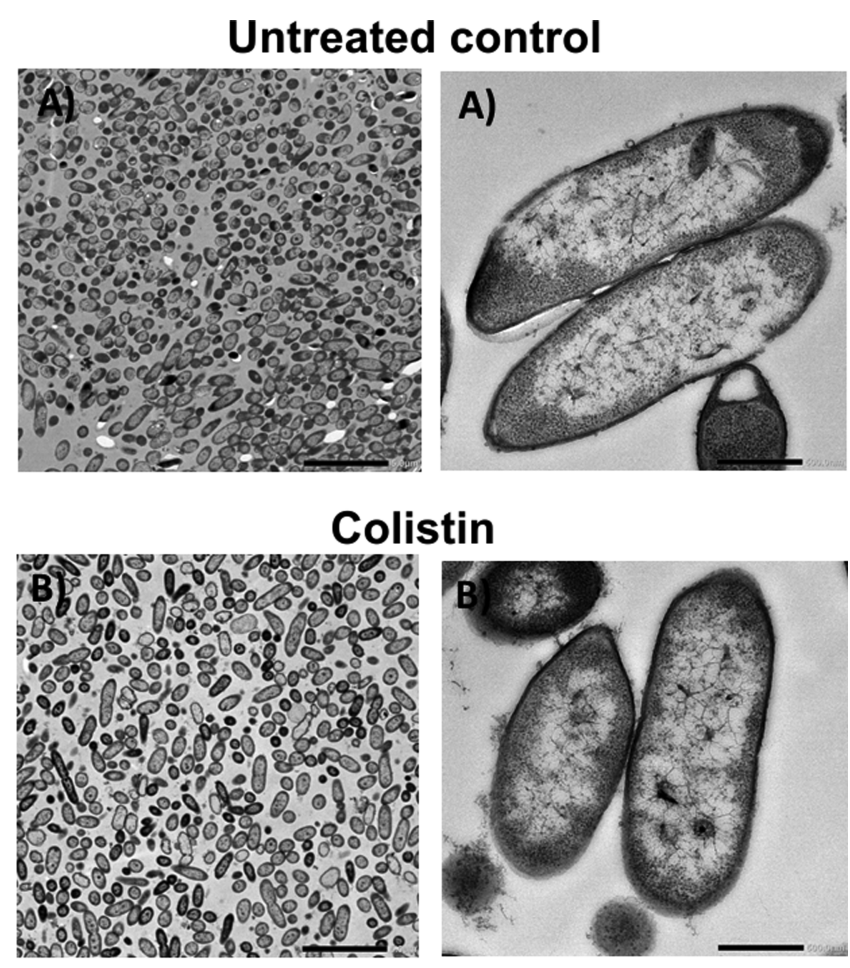

\section{Octapeptin A3}
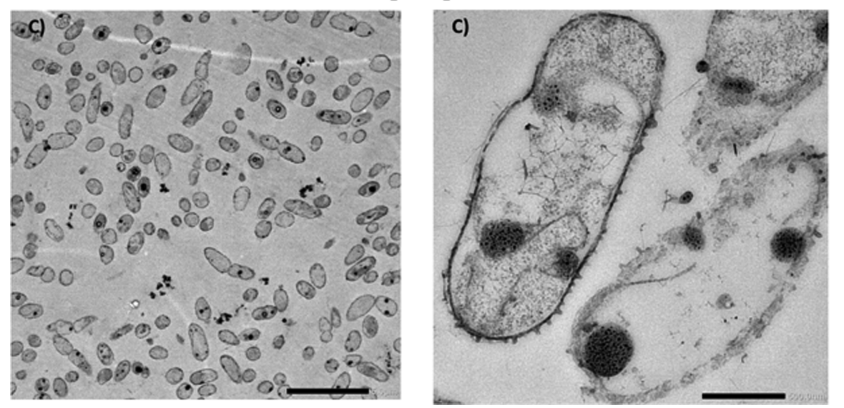

Figure 6. Electron microscopy images (magnification: left, $5 \mu \mathrm{m}$; right, $500 \mathrm{~nm}$ ) of biofilm disruption of the polymyxin-resistant $P$. aeruginosa CF isolate FADDI-PA066 (A) untreated or treated with the respective 1× MIC: (B) colistin (128 mg/L); (C) octapeptin $A_{3}(16 \mathrm{mg} / \mathrm{L})$.

Mucins are high molecular weight $(0.5-40 \mathrm{MDa})$ highly glycosylated proteins. ${ }^{44,45}$ Apart from chronic obstruction pulmonary disease and CF patients, who express very high mucin levels, the mucin content in healthy individuals ranges from $2 \%$ to $5 \%$ by weight of lung mucus. ${ }^{44-47}$ The addition of $50 \%(\mathrm{w} / \mathrm{v})$ mucin to the bacterial growth media at levels relevant to the $\mathrm{CF}$ diseased state ${ }^{48}$ produced a marked decrease in the antibacterial activity of all of the lipopeptides against the two polymyxin-susceptible P. aeruginosa strains FADDI-PA020 and FADDI-PA021 (Figures S3 and S4). Similarly, against the polymyxin-resistant strain FADDIPA066, mucin reduced the antibacterial activity of FADDI-003, polymyxin $A_{2}$, and octapeptin $A_{3}$; the impact of mucin on the activity of polymyxin $B$ and colistin was not noticeable as these lipopeptides are inactive against this strain (Figure S5). These findings are in line with the previous report from Huang et al., who employed dialysis to show that colistin and polymyxin $\mathrm{B}$ avidly bind to mucin. ${ }^{32}$

$P$. aeruginosa $\mathrm{CF}$ lung infection and biofilm formation induces an inflammatory response and a neutrophil-rich environment. ${ }^{49}$ F-actin/DNA bundles released from necrotic neutrophils stimulate biofilm formation by $P$. aeruginosa and are major components of the biofilm matrix itself. ${ }^{50}$ F-actin/DNA inhibited the activity of FADDI-003 against the polymyxin-sensitive isolate FADDI-PA020, whereas the activity of polymyxin $B$, colistin, polymyxin $A_{2}$, and octapeptin $A_{3}$ was only marginally affected (Figures S3 and S4). Conversely, F-actin/DNA inhibited the activity of polymyxin $B$, colistin, polymyxin $A_{2}$, and octapeptin $A_{3}$ against the polymyxin-sensitive isolate FADDI-PA021, whereas the activity of FADDI-003 was unaffected. F-actin/DNA marginally inhibited the activity of polymyxin $B$ against the polymyxinresistant FADDI-PA066 but substantially inhibited the activity of polymyxin $A_{2}$ and octapeptin $A_{3}$. There was no impact on the activity of colistin and FADDI-003 (Figure S5). The addition of DNA per se to the growth media marginally impacted the activity of polymyxin $\mathrm{B}$ and colistin against the polymyxin-sensitive strains FADDI-PA020 and FADDI-PA021, whereas the activity of FADDI-003, polymyxin $A_{2}$, and octapeptin $A_{3}$ was significantly inhibited (Figures S3 and S4). A similar trend was evident in the case of the polymyxin-resistant strain FADDI-066 (Figure S5).

The primary mode of action of polymyxins involves an initial binding event to the lipid A portion of LPS in the Gram-negative outer membrane; ${ }^{51}$ it is also well-known that isolated LPS avidly binds to polymyxins. ${ }^{52,53}$ Considering that LPS is a key component of bacterial biofilm, we examined the impact of LPS addition to the growth media on the activity of each lipopeptide. Not surprisingly, LPS almost completely inactivated all of the lipopeptides' effects against all three strains (Figures S3-S5).

The addition of phospholipids to the growth media significantly impacted the activity of each lipopeptide against both the polymyxin-sensitive isolates FADDI-PA020 and FADDI-PA021 (Figures S3 and S4). In contrast, when treating the polymyxinresistant strain FADDI-PA066, phospholipids only marginally impacted the activity of FADDI-003, polymyxin $A_{2}$, and octapeptin $A_{3}$, whereas the impact on the activity of polymyxin $\mathrm{B}$ and colistin was not discernible (Figure S5).

Pulmonary surfactant is a complex surface-active mixture of phospholipids and proteins that forms a film that lines the alveolar air-surface interface. ${ }^{41,54}$ Notably, it has been reported that pulmonary surfactant interacts with and inhibits the antibacterial activity of the lipopeptide daptomycin, which precludes it clinical use for the treatment of pneumonia. ${ }^{41}$ Moreover, cationic peptides have been shown to electrostatically interact with surfactant lipids and inhibit the surface activity of pulmonary surfactant, possibly by the formation of a mixed lipid-polyamino acid film. ${ }^{41}$ The addition of bovine pulmonary surfactant to the growth media significantly inhibited the antibacterial activity of each lipopeptide against all three strains; in addition, the inhibition was more pronounced against the two polymyxin-sensitive isolates (Figures $\mathrm{S} 3-\mathrm{S} 5$ ).

\section{CONCLUSIONS}

There is a major unmet medical need for effective antibiotic therapies with minimal adverse effects for lung infections in CF patients. In the early stages of $P$. aeruginosa CF lung colonization, a nonmucoid planktonic (nonbiofilm) form of growth predominately exists, which can be eradicated with most current antibiotic treatment. ${ }^{55-57}$ However, recurrent $P$. aeruginosa CF lung infections often transition to the mucoid form (biofilm), which are resistant to current antibiotics. ${ }^{55,58}$ Hence, the development of next generation polymyxin lipopeptides targeting $P$. aeruginosa CF lung infections is paramount if we are to provide effective therapies. Sputum binding in the airways is known to reduce the antibacterial efficacy of inhaled lipopeptide antibiotics such as 
colistin. $^{59}$ The polymyxin lipopeptides described herein were proven to have good antibacterial activity against polymyxinsensitive and polymyxin-resistant $P$. aeruginosa $\mathrm{CF}$ isolates growing in sputum. Moreover, our data highlighted that specific sputum component biomolecules can sequester the antibacterial activity of more hydrophobic lipopeptides. Overall, the present study lays the foundations for the development of these lipopeptides as antibiotics to treat life-threatening multidrug resistance (MDR) P. aeruginosa CF lung infections.

\section{EXPERIMENTAL SECTION}

Lipopeptides were prepared in Milli- $\mathrm{Q}$ water (Millipore, Australia) and then filtered through $0.22 \mu \mathrm{m}$ syringe filters (Sartorius, Australia). Bovine pulmonary surfactant (beractant) was obtained from Abbvie (Australia). Lipopeptides were synthesized as previously described in detail. ${ }^{60,61}$ All other reagents were of the highest commercial grade available (Sigma-Aldrich Australia).

A range of $P$. aeruginosa isolates, including CF specific isolates, were selected for the initial susceptibility testing (Table 1). Paired polymyxin-susceptible and -resistant $P$. aeruginosa $\mathrm{CF}$ clinical isolates (FADDI-PA020 [polymyxin B MIC $=2 \mathrm{mg} / \mathrm{L}$; FADDI-PA066 [polymyxin B MIC $=32 \mathrm{mg} / \mathrm{L}$ ]) were used in the artificial sputum assays. ${ }^{62} \mathrm{~A}$ polymyxin-susceptible reference strain, FADDI-PA021 (polymyxin B MIC $=1 \mathrm{mg} / \mathrm{L}$ ), was also tested. Resistance to polymyxin B was defined as MICs of $>4 \mathrm{mg} / \mathrm{L}$, according to the European Committee on Antimicrobial Susceptibilty Testing (EUCAST) clinical breakpoints. ${ }^{63}$

Bacteria were stored at $-80^{\circ} \mathrm{C}$ in tryptone soya broth (Oxoid, Australia) and subcultured onto nutrient agar plates (Medium Preparation Unit, University of Melbourne, Australia). The overnight broth cultures were grown in $5 \mathrm{~mL}$ of cation-adjusted Mueller-Hinton broth (CAMHB, Oxoid, Australia), from which a 1 in 100 dilution was made in fresh broth (midlogarithmic cultures; optical density (OD) at $500 \mathrm{~nm}=0.4$ to 0.6 ). Cultures were incubated at $37^{\circ} \mathrm{C}$ in a shaking water bath $(180 \mathrm{rpm})$.

Minimum inhibitory concentration (MIC) assays for each lipopeptide against a range of $\mathrm{CF}$ isolates were conducted according to the Clinical and Laboratory Standards Institute (Table 1). ${ }^{64}$ CAMHB in 96-well polypropylene microtiter plates was used for all MIC experiments. Bacterial suspensions $(100 \mu \mathrm{L}$ in CAMHB containing $10^{6}$ colony forming units $[\mathrm{CFU}] / \mathrm{mL}$ ) and increasing concentrations of a lipopeptide ( 0 to $256 \mathrm{mg} / \mathrm{L})$ were inoculated into the well containing $100 \mu \mathrm{L}$ of CAMHB. The lowest concentration at which visible growth was inhibited following $18 \mathrm{~h}$ of incubation at $37^{\circ} \mathrm{C}$ was defined as the MIC. For cell viability, wells were determined by sampling wells at lipopeptide concentrations greater than the MIC. The samples were diluted in saline and plated onto nutrient agar. Following incubation at $37{ }^{\circ} \mathrm{C}$ for $20 \mathrm{~h}$, the CFU was determined; the limit of detection was $10 \mathrm{CFU} / \mathrm{mL}$.

The artificial sputum media assays (ASM) were performed with the paired $P$. aeruginosa strains FADDI-PA020 (polymyxin $\mathrm{B} \mathrm{MIC}=2 \mathrm{mg} / \mathrm{L}$ ) and FADDI-PA066 (polymyxin B MIC = $32 \mathrm{mg} / \mathrm{L}$ ); FADDI-PA021 (polymyxin B MIC = $1 \mathrm{mg} / \mathrm{L}$ ) was used as the reference strain. The ASM assays were performed in a 24-well plate format. ASM faithfully mimics CF patient sputum as described in detail by Kirchner et al. ${ }^{65}$ and O'Callaghan et al. ${ }^{66}$ In brief, $4 \mathrm{~g}$ of salmon sperm DNA and $5 \mathrm{~g}$ of mucin from porcine stomach were slowly dissolved overnight in $250 \mathrm{~mL}$ of sterile Milli-Q water. Then, the DNA/mucin solution was combined with $0.25 \mathrm{~g}$ of each essential and nonessential $\mathrm{L}$-amino acid in $100 \mathrm{~mL}$ of sterile water (L-alanine, L-arginine, $\mathrm{L}(+)$-asparagine monohydrate, $\mathrm{L}(+)$-aspartic acid, $\mathrm{L}(+)$-glutamic acid, L-glutamine, glycine, L-histidine, L-isoleucine, L-leucine, L(+)-lysine monohydrochloride, L-methionine, L-phenylalanine, L-proline, L-serine, L-threonine, L(-)-tryptophan, and L-valine) (exception: dissolve $0.25 \mathrm{~g}$ of each L-cysteine in $25 \mathrm{~mL}$ of $0.5 \mathrm{M}$ potassium hydroxide and L-tyrosine in $25 \mathrm{~mL}$ of sterile water), $5.9 \mathrm{mg}$ of diethylenetriaminepentaacetic acid (DTPA), $5 \mathrm{~g}$ of $\mathrm{NaCl}, 2.2 \mathrm{~g}$ of $\mathrm{KCl}$ in $100 \mathrm{~mL}$ of sterile water, and $5 \mathrm{~mL}$ of egg yolk emulsion. Subsequently, $\mathrm{pH}$ was adjusted to 6.9 with $1 \mathrm{M}$ Tris ( $\mathrm{pH} 8.5$ ), and the volume was brought up to $1 \mathrm{~L}$ with sterile water. The ASM was then filter sterilized at $4{ }^{\circ} \mathrm{C}$ in the dark using a Vacuubrand ME 2 diaphragm vacuum pump and Millipore Steritop filter units (pore and neck size of $0.22 \mu \mathrm{m}$ and $45 \mathrm{~mm}$ ). ${ }^{65} \mathrm{P}$. aeruginosa isolates were subcultured onto nutrient agar plates and incubated at $37^{\circ} \mathrm{C}$ overnight. A randomly selected colony of each isolate was grown overnight in $10 \mathrm{~mL}$ of $\mathrm{CAMBH}$ at $37^{\circ} \mathrm{C}$. CAMBH was used to dilute the overnight culture to an OD of $\sim 0.05$ and then subsequently diluted 1:100 in fresh ASM. The total volume in each well was $2 \mathrm{~mL}$. Parafilm was used to secure plates which were then incubated for 3 days aerobically at $37{ }^{\circ} \mathrm{C}$, wherein the $P$. aeruginosa biofilms were developed. After 3 days, lipopeptides were added at concentrations ranging from 8 to $256 \mathrm{mg} / \mathrm{L}$ and incubated for a further $24 \mathrm{~h}$. Disruption of the biofilm was performed enzymatically $[100 \mu \mathrm{L}$ of $100 \mathrm{mg} / \mathrm{mL}$ cellulase $(\mathrm{pH}$ adjusted to 4.6 with $\mathrm{NaOH}$; diluted in $9.6 \mathrm{~g} / \mathrm{L}$ citrate ], and then, it was incubated for $1 \mathrm{~h}$ at $37{ }^{\circ} \mathrm{C}$. Pipetting was employed to further manually disrupt the biofilms. Resazurin was added to each well $[100 \mu \mathrm{L}$ of $0.02 \%(\mathrm{v} / \mathrm{v})]$, and the wells were further incubated for $2 \mathrm{~h}$ at $37{ }^{\circ} \mathrm{C}$. Four replicates were conducted. ENVISION plate reader (PerkinElmer, Australia) set at an excitation wavelength of $530 \mathrm{~nm}$ and an emission wavelength of $590 \mathrm{~nm}$ was used to measure fluorescence. The cell viability was calculated as (mean fluorescence of lipopeptide treated wells/mean fluorescence untreated control wells) $\times 100 \%$.

Transmission electron microscopy was conducted as previously described. ${ }^{67,68}$ In brief, one colony of P. aeruginosa FADDIPA066 was randomly selected and used to prepare a biofilm culture of which $10 \mathrm{~mL}$ of log-phase cultures (at $\sim 10^{8} \mathrm{CFU} / \mathrm{mL}$ ) in CAMHB were obtained. The tubes were treated with $128 \mathrm{mg} / \mathrm{L}$ colistin or $16 \mathrm{mg} / \mathrm{L}$ octapeptin $\mathrm{A}_{3}$ and incubated for $1 \mathrm{~h}$ at $37^{\circ} \mathrm{C}$ followed by centrifugation at $3220 \mathrm{~g}$ for $10 \mathrm{~min}$. Bacterial cells were fixed with $2.5 \%$ glutaraldehyde, washed, and imaged as described in detail. ${ }^{67,68}$

Isolates were subcultured on nutrient agar plates and then incubated at $37{ }^{\circ} \mathrm{C}$ overnight. A randomly selected colony was grown overnight in $10 \mathrm{~mL}$ of $\mathrm{CAMBH}$ at $37{ }^{\circ} \mathrm{C}$. The overnight culture was then grown in $10 \mathrm{~mL}$ of CAMHB, from which a 1 in 100 dilution was performed in fresh broth to prepare midlogarithmic cultures with $\mathrm{OD}_{500 \mathrm{~nm}}=0.4-0.6$. All broth cultures were incubated at $37^{\circ} \mathrm{C}$ in a shaking water bath $(180 \mathrm{rpm})$. The culture was diluted in $\mathrm{CAMBH}$ to an $\mathrm{OD}$ of $\sim 0.05$. Sputum composite biomolecules at concentrations of $125 \mathrm{mg} / \mathrm{L}$ (F-actin/ DNA, DNA, mucin [MUC], phospholipids [PL], surfactant [SUR], or LPS) were coincubated in a 24-well plate for $3 \mathrm{~h}$ with lipopeptides at a concentration of $2 \mathrm{mg} / \mathrm{L}$. A sample was taken from each well, plated using a spiral plater, and further incubated overnight at $37{ }^{\circ} \mathrm{C}$. A ProtoCOL automated colony counter (Synbiosis, Cambridge, United Kingdom) was used to count colonies; the detection limit was $10 \mathrm{CFU} / \mathrm{mL}$.

\section{ASSOCIATED CONTENT}

\section{S Supporting Information}

The Supporting Information is available free of charge on the ACS Publications website at DOI: 10.1021/acsinfecdis.7b00238. 
Activity of polymyxin B, colistin, FADDI-003, polymyxin $\mathrm{A} 2$, and octapeptin $\mathrm{A} 3$ against the $P$. aeruginosa reference strain; activity of polymyxin B, colistin, FADDI-003, polymyxin $\mathrm{A} 2$, and octapeptin $\mathrm{A} 3$ against the $P$. aeruginosa reference strain; influence of sputum biomolecules on the activity of polymyxin B, colistin, FADDI-003, octapeptin $\mathrm{A} 3$, and polymyxin A2 against the $P$. aeruginosa reference strain; influence of sputum biomolecules on the activity of polymyxin B, colistin, FADDI-003, octapeptin A3, and polymyxin A2 against $P$. aeruginosa; influence of sputum biomolecules on the activity of polymyxin B, colistin, FADDI-003, octapeptin A3, and polymyxin A2 against $P$. aeruginosa (PDF)

\section{AUTHOR INFORMATION}

\section{Corresponding Authors}

*Phone: +61 39903 9539. Fax: +61 39903 9583. E-mail: Tony. Velkov@unimelb.edu.au (T.V.).

*E-mail: Jian.Li@monash.edu (J.L.).

ORCID

Elena K. Schneider-Futschik: 0000-0001-6044-4824

Daniel Hoyer: 0000-0002-1405-7089

Tony Velkov: 0000-0002-0017-7952

\section{Author Contributions}

$\nabla_{\text {J.L. and T.V. are joint senior authors. }}$

\section{Notes}

The authors declare no competing financial interest.

\section{ACKNOWLEDGMENTS}

J.L. and T.V. are supported by research grants from the National Institute of Allergy and Infectious Diseases of the National Institutes of Health (R01A1070896 and R01AI079330). J.L. and T.V. are also supported by the Australian National Health and Medical Research Council (NHMRC). The authors gratefully thank Dr. Simon Crawford for the help on the transmission electron microscope. The content is solely the responsibility of the authors and does not necessarily represent the official views of the National Institute of Allergy and Infectious Diseases or the National Institutes of Health. E.K.S.-F. is the appointed Young Ambassador to Australia (American Society for Microbiology) and is supported by the Australian Postgraduate Award and the Postgraduate Publication Award.

\section{ABBREVIATIONS}

ASM, artificial sputum media; CAMHB, cation-adjusted Mueller-Hinton broth; CF, cystic fibrosis; CFTR, cystic fibrosis transmembrane conductance regulator; CFU, colony forming units; DA, Dalton; DNA, deoxyribonucleic acid; EUCAST, European Committee on Antimicrobial Susceptibilty Testing; h, hour; L, liter; LPS, lipopolysaccharide; mcr-1, mobilized colistin resistance; MDR, multidrug resistance; $\mathrm{mg}$, milligram; MIC, minimum inhibitory concentration; MUC, mucin; OD, optical density; P. aeruginosa, Pseudomonas aeuriginosa; PA, Pseudomonas aeuriginosa; PD, pharmacodynamic; PK, pharmacokinetic; PL, phospholipids; rpm, revolutions per minute; SUR, surfactant

\section{REFERENCES}

(1) Bobadilla, J. L., Macek, M., Jr., Fine, J. P., and Farrell, P. M. (2002) Cystic fibrosis: a worldwide analysis of CFTR mutations-correlation with incidence data and application to screening. Hum. Mutat. 19 (6), 575-606.
(2) Lyczak, J. B., Cannon, C. L., and Pier, G. B. (2002) Lung infections associated with cystic fibrosis. Clin Microbiol Rev. 15 (2), 194-222.

(3) Ciofu, O., Tolker-Nielsen, T., Jensen, P. O., Wang, H., and Hoiby, N. (2015) Antimicrobial resistance, respiratory tract infections and role of biofilms in lung infections in cystic fibrosis patients. Adv. Drug Delivery Rev. 85, 7-23.

(4) Henry, R. L., Mellis, C. M., and Petrovic, L. (1992) Mucoid Pseudomonas aeruginosa is a marker of poor survival in cystic fibrosis. Ped Pul 12 (3), 158-61.

(5) Emerson, J., Rosenfeld, M., McNamara, S., Ramsey, B., and Gibson, R. L. (2002) Pseudomonas aeruginosa and other predictors of mortality and morbidity in young children with cystic fibrosis. Ped Pul 34 (2), 91100.

(6) Ramsey, B. W., Pepe, M. S., Quan, J. M., Otto, K. L., Montgomery, A. B., Williams-Warren, J., Vasiljev, K. M., Borowitz, D., Bowman, C. M., Marshall, B. C., Marshall, S., and Smith, A. L. (1999) Intermittent administration of inhaled tobramycin in patients with cystic fibrosis. Cystic Fibrosis Inhaled Tobramycin Study Group. N. Engl. J. Med. 340 (1), 23-30.

(7) Sawicki, G. S., Signorovitch, J. E., Zhang, J., Latremouille-Viau, D., von Wartburg, M., Wu, E. Q., and Shi, L. (2012) Reduced mortality in cystic fibrosis patients treated with tobramycin inhalation solution. Ped Pul 47 (1), 44-52.

(8) Frederiksen, B., Koch, C., and Hoiby, N. (1997) Antibiotic treatment of initial colonization with Pseudomonas aeruginosa postpones chronic infection and prevents deterioration of pulmonary function in cystic fibrosis. Ped Pul 23 (5), 330-5.

(9) Dittrich, A. M. (2017) [Chronic Pseudomonas aeruginosa airway colonization in cystic fibrosis patients: Prevention concepts]. Internist 58 (11), 1133-1141.

(10) Rohde, G. G. U., and Welte, T. (2017) [Pseudomonas aeruginosa infections in chronic obstructive pulmonary disease: Role of long-term antibiotic treatment]. Internist 58 (11), 1142-1149.

(11) Velkov, T., Roberts, K. D., Nation, R. L., Thompson, P. E., and Li, J. (2013) Pharmacology of polymyxins: new insights into an 'old' class of antibiotics. Future Microbiol. 8 (6), 711-24.

(12) Bratu, S., Tolaney, P., Karumudi, U., Quale, J., Mooty, M., Nichani, S., and Landman, D. (2005) Carbapenemase-producing Klebsiella pneumoniae in Brooklyn, NY: molecular epidemiology and in vitro activity of polymyxin B and other agents. J. Antimicrob. Chemother. 56 (1), 128-132.

(13) Elemam, A., Rahimian, J., and Mandell, W. (2009) Infection with panresistant Klebsiella pneumoniae: a report of 2 cases and a brief review of the literature. Clin. Infect. Dis. 49 (2), 271-274.

(14) Li, J., Nation, R. L., Turnidge, J. D., Milne, R. W., Coulthard, K., Rayner, C. R., and Paterson, D. L. (2006) Colistin: the re-emerging antibiotic for multidrug-resistant Gram-negative bacterial infections. Lancet Infect. Dis. 6 (9), 589-601.

(15) Zavascki, A. P., Goldani, L. Z., Li, J., and Nation, R. L. (2007) Polymyxin B for the treatment of multidrug-resistant pathogens: a critical review. J. Antimicrob. Chemother. 60 (6), 1206-1215.

(16) Liu, Y. Y., Wang, Y., Walsh, T. R., Yi, L. X., Zhang, R., Spencer, J., Doi, Y., Tian, G., Dong, B., Huang, X., Yu, L. F., Gu, D., Ren, H., Chen, X., Lv, L., He, D., Zhou, H., Liang, Z., Liu, J. H., and Shen, J. (2016) Emergence of plasmid-mediated colistin resistance mechanism MCR-1 in animals and human beings in China: a microbiological and molecular biological study. Lancet Infect. Dis. 16 (2), 161-8.

(17) Anwar, H., and Costerton, J. W. (1990) Enhanced activity of combination of tobramycin and piperacillin for eradication of sessile biofilm cells of Pseudomonas aeruginosa. Antimicrob. Agents Chemother. 34 (9), 1666-71.

(18) Ceri, H., Olson, M. E., Stremick, C., Read, R. R., Morck, D., and Buret, A. (1999) The Calgary Biofilm Device: new technology for rapid determination of antibiotic susceptibilities of bacterial biofilms. J. Clin Microb 37 (6), 1771-1776.

(19) Moskowitz, S. M., Foster, J. M., Emerson, J., and Burns, J. L. (2004) Clinically feasible biofilm susceptibility assay for isolates of Pseudomonas aeruginosa from patients with cystic fibrosis. J. Clin Microb 42 (5), 1915-22. 
(20) Pamp, S. J., Gjermansen, M., Johansen, H. K., and Tolker-Nielsen, T. (2008) Tolerance to the antimicrobial peptide colistin in Pseudomonas aeruginosa biofilms is linked to metabolically active cells, and depends on the pmr and mexAB-oprM genes. Mol. Microbiol. 68 (1), 223-40.

(21) Kato, T., and Shoji, T. (1980) The structure of octapeptin D (studies on antibiotics from the genus Bacillus. XXVIII). J. Antibiot. 33 (2), 186-91.

(22) Konishi, M., Sugawara, K., Tomita, K., Matsumoto, K., Miyaki, T., Fujisawa, K., Tsukiura, H., and Kawaguchi, H. (1983) Bu-2470, a new peptide antibiotic complex. I. Production, isolation and properties of $\mathrm{Bu}$ 2470 A, B1 and B2. J. Antibiot. 36 (6), 625-33.

(23) Meyers, E., Brown, W. E., Principe, P. A., Rathnum, M. L., and Parker, W. L. (1973) EM49, a new peptide antibiotic. I. Fermentation, isolation, and preliminary characterization. J. Antibiot. 26 (8), 444-8.

(24) Meyers, E., Pansy, F. E., Basch, H. I., McRipley, R. J., Slusarchyk, D. S., Graham, S. F., and Trejo, W. H. (1973) EM49, a new peptide antibiotic. 3. biological characterization in vitro and in vivo. J. Antibiot. 26 (8), 457-62.

(25) Qian, C. D., Wu, X. C., Teng, Y., Zhao, W. P., Li, O., Fang, S. G., Huang, Z. H., and Gao, H. C. (2012) Battacin (Octapeptin B5), a new cyclic lipopeptide antibiotic from Paenibacillus tianmuensis active against multidrug-resistant Gram-negative bacteria. Antimicrob. Agents Chemother. 56 (3), 1458-1465.

(26) Shoji, J., Hinoo, H., Wakisaka, Y., Koizumi, K., and Mayama, M. (1976) Isolation of a new antibiotic 333-25, related to antibiotic EM 49. (Studies on antibiotics from the genus Bacillus. XI). J. Antibiot (Tokyo) 29 (5), 516-520.

(27) Storm, D. R., Rosenthal, K. S., and Swanson, P. E. (1977) Polymyxin and related peptide antibiotics. Annu. Rev. Biochem. 46, 72363.

(28) Kawaguchi, H., Tsukiura, H., Fujisawa, K. I., and Numata, K. I. (1975) Antibiotic BU-1880, Google Patents. Japanese patent 7485295 (1974).

(29) Lin, Y. W., Zhou, Q. T., Cheah, S. E., Zhao, J., Chen, K., Wang, J., Chan, H. K., and Li, J. (2017) Pharmacokinetics/Pharmacodynamics of Pulmonary Delivery of Colistin against Pseudomonas aeruginosa in a Mouse Lung Infection Model. Antimicrob. Agents Chemother. 61 (3), e02025-16.

(30) Ahmed, M. U., Velkov, T., Lin, Y. W., Yun, B., Nowell, C. J., Zhou, F., Zhou, Q. T., Chan, K., Azad, M. A. K., and Li, J. (2017) Potential Toxicity of Polymyxins in Human Lung Epithelial Cells. Antimicrob. Agents Chemother. 61 (6), e02690-16.

(31) Azad, M. A. K., Sivanesan, S., Wang, J., Chen, K., Nation, R. L., Thompson, P. E., Roberts, K. D., Velkov, T., and Li, J. (2018) Methionine Ameliorates Polymyxin-Induced Nephrotoxicity by Attenuating Cellular Oxidative Stress. Antimicrob. Agents Chemother. 62 (1), e01254-17.

(32) Huang, J. X., Blaskovich, M. A., Pelingon, R., Ramu, S., Kavanagh, A., Elliott, A. G., Butler, M. S., Montgomery, A. B., and Cooper, M. A. (2015) Mucin Binding Reduces Colistin Antimicrobial Activity. Antimicrob. Agents Chemother. 59 (10), 5925-31.

(33) Mendelman, P. M., Smith, A. L., Levy, J., Weber, A., Ramsey, B., and Davis, R. L. (1985) Aminoglycoside penetration, inactivation, and efficacy in cystic fibrosis sputum. Am. Rev. Respir. Dis. 132 (4), 761-765.

(34) Sriramulu, D. D., Lunsdorf, H., Lam, J. S., and Romling, U. (2005) Microcolony formation: a novel biofilm model of Pseudomonas aeruginosa for the cystic fibrosis lung. J. Med. Microbiol. 54 (7), 667676.

(35) Velkov, T., Bergen, P. J., Lora-Tamayo, J., Landersdorfer, C. B., and Li, J. (2013) PK/PD models in antibacterial development. Curr. Opin. Microbiol. 16 (5), 573-9.

(36) Werner, E., Roe, F., Bugnicourt, A., Franklin, M. J., Heydorn, A., Molin, S., Pitts, B., and Stewart, P. S. (2004) Stratified growth in Pseudomonas aeruginosa biofilms. Appl. Envir Microb 70 (10), 618896.

(37) Hoiby, N., Krogh Johansen, H., Moser, C., Song, Z., Ciofu, O., and Kharazmi, A. (2001) Pseudomonas aeruginosa and the in vitro and in vivo biofilm mode of growth. Microbes Infect. 3 (1), 23-35.
(38) Abdulkarim, M., Agulló, N., Cattoz, B., Griffiths, P., BernkopSchnürch, A., Borros, S. G., and Gumbleton, M. (2015) Nanoparticle diffusion within intestinal mucus: Three-dimensional response analysis dissecting the impact of particle surface charge, size and heterogeneity across polyelectrolyte, pegylated and viral particles. Eur. J. Pharm. Biopharm. 97 (Part A), 230-238.

(39) Koike, M., Iida, K., and Matsuo, T. (1969) Electron microscopic studies on mode of action of polymyxin. J. Bacteriol. 97 (1), 448-452.

(40) Hunt, B. E., Weber, A., Berger, A., Ramsey, B., and Smith, A. L. (1995) Macromolecular mechanisms of sputum inhibition of tobramycin activity. Antimicrob. Agents Chemother. 39 (1), 34-9.

(41) Silverman, J. A., Mortin, L. I., Vanpraagh, A. D., Li, T., and Alder, J. (2005) Inhibition of daptomycin by pulmonary surfactant: in vitro modeling and clinical impact. J. Infect. Dis. 191 (12), 2149-52.

(42) Levy, J., Smith, A. L., Kenny, M. A., Ramsey, B., and Schoenknecht, F. D. (1983) Bioactivity of gentamicin in purulent sputum from patients with cystic fibrosis or bronchiectasis: comparison with activity in serum. J. Infect. Dis. 148 (6), 1069-76.

(43) Ramphal, R., Lhermitte, M., Filliat, M., and Roussel, P. (1988) The binding of anti-pseudomonal antibiotics to macromolecules from cystic fibrosis sputum. J. Antimicrob. Chemother. 22 (4), 483-90.

(44) Lai, S. K., Wang, Y. Y., and Hanes, J. (2009) Mucus-penetrating nanoparticles for drug and gene delivery to mucosal tissues. Adv. Drug Delivery Rev. 61 (2), 158-71.

(45) Cone, R. A. (2009) Barrier properties of mucus. Adv. Drug Delivery Rev. 61 (2), 75-85.

(46) Samet, J. M., and Cheng, P. W. (1994) The role of airway mucus in pulmonary toxicology. Environ. Health Perspect 102 (Suppl 2), 89103.

(47) Quraishi, M. S., Jones, N. S., and Mason, J. (1998) The rheology of nasal mucus: a review. Clin Otolaryngol Allied Sci. 23 (5), 403-13.

(48) Clarke, S. W., and Pavia, D. (1980) Lung mucus production and mucociliary clearance: methods of assessment. Br. J. Clin. Pharmacol. 9 (6), 537-46.

(49) Parks, Q. M., Young, R. L., Poch, K. R., Malcolm, K. C., Vasil, M. L., and Nick, J. A. (2009) Neutrophil enhancement of Pseudomonas aeruginosa biofilm development: human F-actin and DNA as targets for therapy. J. Med. Microbiol. 58 (Pt 4), 492-502.

(50) Tolker-Nielsen, T., and Høiby, N. (2009) Extracellular DNA and F-actin as targets in antibiofilm cystic fibrosis therapy. Future Microbiol. 4 (6), 645-647.

(51) Velkov, T., Thompson, P. E., Nation, R. L., and Li, J. (2010) Structure-activity relationships of polymyxin antibiotics. J. Med. Chem. 53 (5), 1898-916.

(52) Soon, R. L., Velkov, T., Chiu, F., Thompson, P. E., Kancharla, R., Roberts, K., Larson, I., Nation, R. L., and Li, J. (2011) Design, synthesis, and evaluation of a new fluorescent probe for measuring polymyxinlipopolysaccharide binding interactions. Anal. Biochem. 409 (2), 27383.

(53) Jin, L., Li, J., Nation, R. L., and Nicolazzo, J. A. (2012) Effect of systemic infection induced by Pseudomonas aeruginosa on the brain uptake of colistin in mice. Antimicrob. Agents Chemother. 56 (10), 52406.

(54) Glasser, J. R., and Mallampalli, R. K. (2012) Surfactant and its role in the pathobiology of pulmonary infection. Microbes Infect. 14 (1), 1725.

(55) Weers, J. (2015) Inhaled antimicrobial therapy - barriers to effective treatment. Adv. Drug Delivery Rev. 85, 24-43.

(56) Doring, G., Flume, P., Heijerman, H., and Elborn, J. S. (2012) Treatment of lung infection in patients with cystic fibrosis: current and future strategies. J. Cystic Fibrosis 11 (6), 461-79.

(57) Hoiby, N., Ciofu, O., and Bjarnsholt, T. (2010) Pseudomonas aeruginosa biofilms in cystic fibrosis. Future Microbiol. 5 (11), 1663-74.

(58) del Pozo, J. L., and Patel, R. (2007) The challenge of treating biofilm-associated bacterial infections. Clin. Pharmacol. Ther. 82 (2), 204-9.

(59) Yun, B., Azad, M. A., Wang, J., Nation, R. L., Thompson, P. E., Roberts, K. D., Velkov, T., and Li, J. (2015) Imaging the distribution of polymyxins in the kidney. J. Antimicrob. Chemother. 70 (3), 827-9. 
(60) Roberts, K. D., Azad, M. A. K., Wang, J., Horne, A. S., Thompson, P. E., Nation, R. L., Velkov, T., and Li, J. (2015) Antimicrobial Activity and Toxicity of the Major Lipopeptide Components of Polymyxin B and Colistin: Last-Line Antibiotics against Multidrug-Resistant GramNegative Bacteria. ACS Infect. Dis. 1 (11), 568-575.

(61) Velkov, T., Roberts, K. D., Nation, R. L., Wang, J., Thompson, P. E., and Li, J. (2014) Teaching 'old' polymyxins new tricks: newgeneration lipopeptides targeting Gram-negative 'superbugs'. ACS Chem. Biol. 9 (5), 1172-1177.

(62) Li, J., Turnidge, J., Milne, R., Nation, R. L., and Coulthard, K. (2001) In vitro pharmacodynamic properties of colistin and colistin methanesulfonate against Pseudomonas aeruginosa isolates from patients with cystic fibrosis. Antimicrob. Agents Chemother. 45 (3), $781-5$.

(63) European Committee on Antimicrobial Susceptibility Testing. (2017) Breakpoint tables for interpretation of MICs and zone diameters, Version 7.1, http://www.eucast.org/fileadmin/src/media/PDFs/ EUCAST_files/Breakpoint_tables/v_7.1_Breakpoint_Tables.pdf.

(64) CLSI. (2010) Performance Standards for Antimicrobial Susceptibility Testing: Twentieth Informational Supplement (M100-S20), CLSI, Wayne, PA, USA

(65) Kirchner, S., Fothergill, J. L., Wright, E. A., James, C. E., Mowat, E., and Winstanley, C. (2012) Use of artificial sputum medium to test antibiotic efficacy against Pseudomonas aeruginosa in conditions more relevant to the cystic fibrosis lung. J. Visualized Exp. 64, e3857.

(66) O'Callaghan, C. H., Morris, A., Kirby, S. M., and Shingler, A. H. (1972) Novel method for detection of beta-lactamases by using a chromogenic cephalosporin substrate. Antimicrob. Agents Chemother. 1 (4), 283-8.

(67) Rahim, N. A., Cheah, S. E., Johnson, M. D., Yu, H. D., Sidjabat, H. E., Boyce, J., Butler, M. S., Cooper, M. A., Fu, J., Paterson, D. L., Nation, R. L., Bergen, P. J., Velkov, T., and Li, J. (2015) Synergistic killing of NDM-producing MDR Klebsiella pneumoniae by two 'old' antibioticspolymyxin B and chloramphenicol. J. Antimicrob. Chemother. 70 (9), $2589-2597$.

(68) Schneider, E. K., Azad, M. A. K., Han, M. L., Zhou, Q., Wang, J. P., Huang, J. X., Cooper, M. A., Doi, Y., Baker, M. A., Bergen, P. J., Muller, M. T., Li, J., and Velkov, T. (2016) An "Unlikely" Pair: The Antimicrobial Synergy of Polymyxin B in Combination with the Cystic Fibrosis Transmembrane Conductance Regulator Drugs KALYDECO and ORKAMBI. ACS Infect. Dis. 2 (7), 478-488. 